\title{
Variation in Thousand Grain Weight of Green Gram Stored in Hermetic and Other Bags
}

\author{
Asha Kumari and Mukesh Shrivastava*
}

Department of Processing \& Food Engineering College of Agricultural Engineering, Dr. Rajendra Prasad Central Agricultural University, Pusa (Samastipur) - 848 125, Bihar, India

*Corresponding author

\section{Keywords \\ Green gram, Hermetic bag, Jute bag, Plastic bag, Polythene bag, Treated, Untreated, Type of bag, Thousand grain weight \\ Article Info \\ Accepted: \\ 17 May 2019 \\ Available Online: \\ 10 June 2019}

\section{A B S T R A C T}

A study was conducted to see the thousand grain weight variation in Green gram stored in different types of bags. Green gram (Vigna radiate) grains were procured from local market, cleaned and graded by two screen cleaner-cum-grader. Storage study was conducted by storing large sized green gram grains in 4 types of bags (jute, plastic, polythene, hermetic) without and with treatment (aluminium phosphide tablets) at 3 different initial moisture contents $(12.34,14.07,16.04 \%$ w.b.). Total 21 such bags having different treatment combinations were kept in laboratory for 33 weeks. Daily observation of ambient temperature and relative humidity was taken throughout the study period. Weekly observations of moisture content were recorded for 27 weeks (jute bags) to 33 weeks (hermetic bags). It was observed that thousand grain weight decreased with advancement of storage duration across all 21 experimental combinations. The overall variation range for thousand grain weight was found between $33.20-49.04 \mathrm{~g}$. Variation was observed more in case of untreated samples as compared to treated samples. Hermetic bags stored green gram was found better with minimum decrease in grain damage (46.03 to $42.58 \mathrm{~g}$ ) even after 33 weeks of storage duration in case of IMC1. Statistical analysis through UNIANOVA revealed that initial moisture content emerged as most significant independent variable to affect thousand grain weights. The interaction of trt*imc affected thousand grain weight most significantly. Hence the hermetic bag could be recommended for storing green gram safely for longer duration without affecting its quality.

\section{Introduction}

Various cereals (wheat, rice etc.), pulses (pigeon pea, gram etc.) and oilseeds (groundnut, soybean) are produced largely in India. India is the world's largest producer and consumer of pulses accounting about $27 \%$ of the total production and about $30 \%$ of total consumption in world. Total production of pulses in India during the year 2013-14 was 18.5 million tons. In the year 2015-16, the pulse production in Bihar has been estimated as 7.35 lakh tons, out of which green gram shared 1.558 lakh tons.

Post-harvest Food Loss (PHL) is defined as measurable qualitative and quantitative food loss along the supply chain, starting at the 
time of harvest till its consumption or other end uses. Post-harvest losses are due to poor production practices, poor post-harvest management practices, lack of grading at farm level, poor packaging, poor transportation, multiple handling, and poor marketing system. Reduction of pre-harvest, harvest and post-harvest losses is indeed a complementary means of increasing the food availability. Storage losses are due to high moisture content of the stored material, the storage condition (high relative humidity), erratic climatic condition, absence of primary processing (cleaning and grading) at farm level and lack of storage facility at production catchment.

A method considered for the prevention of storage losses in airtight storage bags termed as 'airtight storage' or 'hermetic storage' bags. Hermetic storage systems strive to eliminate all exchange of gases between the inside and the outside of a grain storage container/bag. If the gas exchange is low enough, living organisms such as insects within the container/bag will deplete oxygen and produce carbon dioxide until they die or become inactive due to the low oxygen. Hermetic storage bags is a safe, cost-effective storage method that controls insect infestations in addition to preserving the quality of grains, while allowing for pesticidefree, short-term and long-term qualitative and quantitative grain preservation.

Hermetic storage is capable of maintaining relative humidity that preserves grain moisture and prevents mold growth. Hermetic bags need to be validated for its effectiveness in hermetic storage of food grains under Bihar conditions. In response to requests by farmers, traders and private seed companies to determine the effectiveness of hermetic bags for storage of cereals/pulses, a comparative study on storage behavior of green gram different storage bags was made to assess the qualitative and quantitative loss and to validate the advantages of hermetic bags in green gram storage over the conventional storage bags used in the region.

\section{Materials and Methods}

\section{Sample preparation and treatment}

Fresh and healthy green gram pulse grains were procured from local farmer from Muzaffarpur district in Bihar. Cleaning and grading of grains was done in two screen seed cleaner-cum-grader using top screen of 4.0 $\mathrm{mm}$ and bottom screen of $2.5 \mathrm{~mm}$ round holes. Total $210 \mathrm{~kg}$ cleaned and graded green gram grains of $2.64 \mathrm{~mm} \varnothing$ size with moisture content of $12.05 \%$ w.b. were available for storage study. Grains were weighed on a digital platform type balance (WENSER) having $150 \mathrm{~kg}$ capacity and $0.01 \mathrm{~kg}$ sensitivity. The fumigant (Aluminium Phosphide) popularly known as sulphas was used for the chemical treatment whose molecular formula is AlF, molecular weight is $57.955 \mathrm{gm}^{-\mathrm{mole}^{-1}}$ and density is $2.85 \mathrm{gm}$. $\mathrm{cm}^{-3}$. Half sulphas tablet weighing $0.93 \mathrm{~g} \mathrm{kept}$ inside a piece of muslin cloth was placed in the centre of the bag and bag-mouth was closed by tightly twisting the free portion and then tying it by plastic rope.

\section{Experimental variables}

\section{Independent variables}

Type of storage bags: 4 types [Jute (JUT), Plastic (PLS), Polythene (PLY), Hermetic (HER)]

Initial moisture content (IMC) \% w. b.: 3 levels [IMC1-12.32 \%, IMC2-14.04\%, IMC3$16.04 \%$ w.b.]

Treatment: 2 levels [Treated chemically (T), Untreated (UT)] 
Storage duration (weeks): 28 to 34 levels [Jute bags -0 to 27 weeks, Plastic bags 0 to 29 weeks, Polythene bags 0 to 31 weeks, Hermetic bags 0 to 33 weeks]

\section{Dependent variables}

Thousand Grain Weight (TGW)

\section{Observations}

Ambient temperature ${ }^{\circ} \mathrm{C}$ (Daily)

Ambient R.H., \% (Daily)

\section{Experimental design}

Factorial - 4 types of bags $\times 2$ types of treatment $\times 3$ levels of $\mathrm{IMC}=24$ Combinations. But the Hermetic bags were used to store samples without any treatment only, so the total combinations were reduced to 21 as detailed below:

$3 \mathrm{JUT}$ bags $-\mathrm{T}-$ with $\mathrm{IMC}_{1}, \mathrm{IMC}_{2}, \mathrm{IMC}_{3}$ 3 PLY bags - T - with $\mathrm{IMC}_{1}, \mathrm{IMC}_{2}, \mathrm{IMC}_{3}$ 3 PLS bags - T - with $\mathrm{IMC}_{1}, \mathrm{IMC}_{2}, \mathrm{IMC}_{3}$ $3 \mathrm{JUT}$ bags - UT - with $\mathrm{IMC}_{1}, \mathrm{IMC}_{2}, \mathrm{IMC}_{3}$ 3 PLY bags - UT - with $\mathrm{IMC}_{1}, \mathrm{IMC}_{2}, \mathrm{IMC}_{3}$ 3 PLS bags - UT - with $\mathrm{IMC}_{1}, \mathrm{IMC}_{2}, \mathrm{IMC}_{3}$ 3 HER bags - UT - with $\mathrm{IMC}_{1}, \mathrm{IMC}_{2}, \mathrm{IMC}_{3}$

\section{Experimental Methodology}

After determining moisture content of cleaned and graded lot of green gram grains as $12.05 \%$ w.b., the whole lot was subdivided in three sub-lots. Required amount of water was added in two sub-lots which were left for tempering for 24 hours to adjust the moisture within the grain heap for getting two more desired levels of moisture contents. The initial moisture content of all three lots was determined again which were found as $12.34 \%, 14.07 \%, 16.04 \%$ w.b. Then green gram grains were stored in 21 bags as per experimental design. The size of hermetic/polythene bag was $112 \times 61 \mathrm{~cm}$, and of jute/plastic was $83 \times 55 \mathrm{~cm}$ (having capacity of $50 \mathrm{~kg}$ each). For treatment of samples, half tablet $(0.93 \mathrm{~g})$ of sulphas tied in a small piece of muslin cloth was kept in stored grains. The mouth of each bag was tied with the help of plastic rope after evacuating air above the stored grains out of the bag. For observations, samples were drawn from each bag randomly every week. Observations were continued for 27-33 weeks for different bags depending upon the condition of resultant grains.

\section{Determination of moisture content}

The moisture content of sample was determined by standard hot air oven method. The samples were dried in hot air oven at $105 \pm 2^{\circ} \mathrm{C}$ for 24 hours. The moisture content of sample was determined in accordance with AOAC method (Anonymous, 1990) using following formula:

$\mathrm{MC}=\frac{w_{m}}{w_{m+w_{d}}} \times 100$

Where,

$\mathrm{MC}=$ Moisture content, \% w.b.

$\mathrm{W}_{\mathrm{m}}=$ Weight of the moisture evaporated, $\mathrm{g}$

$\mathrm{W}_{\mathrm{d}}=$ Weight of dried sample, $\mathrm{g}$

\section{Determination of thousand grain weight}

At the end of every week of storage period, random samples of 1000 grains were drawn from each bag and each sample was weighed on a digital electronic balance (WENSER) of $2000 \mathrm{~g}$ capacity and of $0.01 \mathrm{~g}$ sensitivity.

\section{Recording of observations}

The ambient temperature and relative humidity were recorded by portable digital temperature/relative humidity meter (ZEAL, $0.1^{\circ} \mathrm{C}, 0.1 \%$ ). 

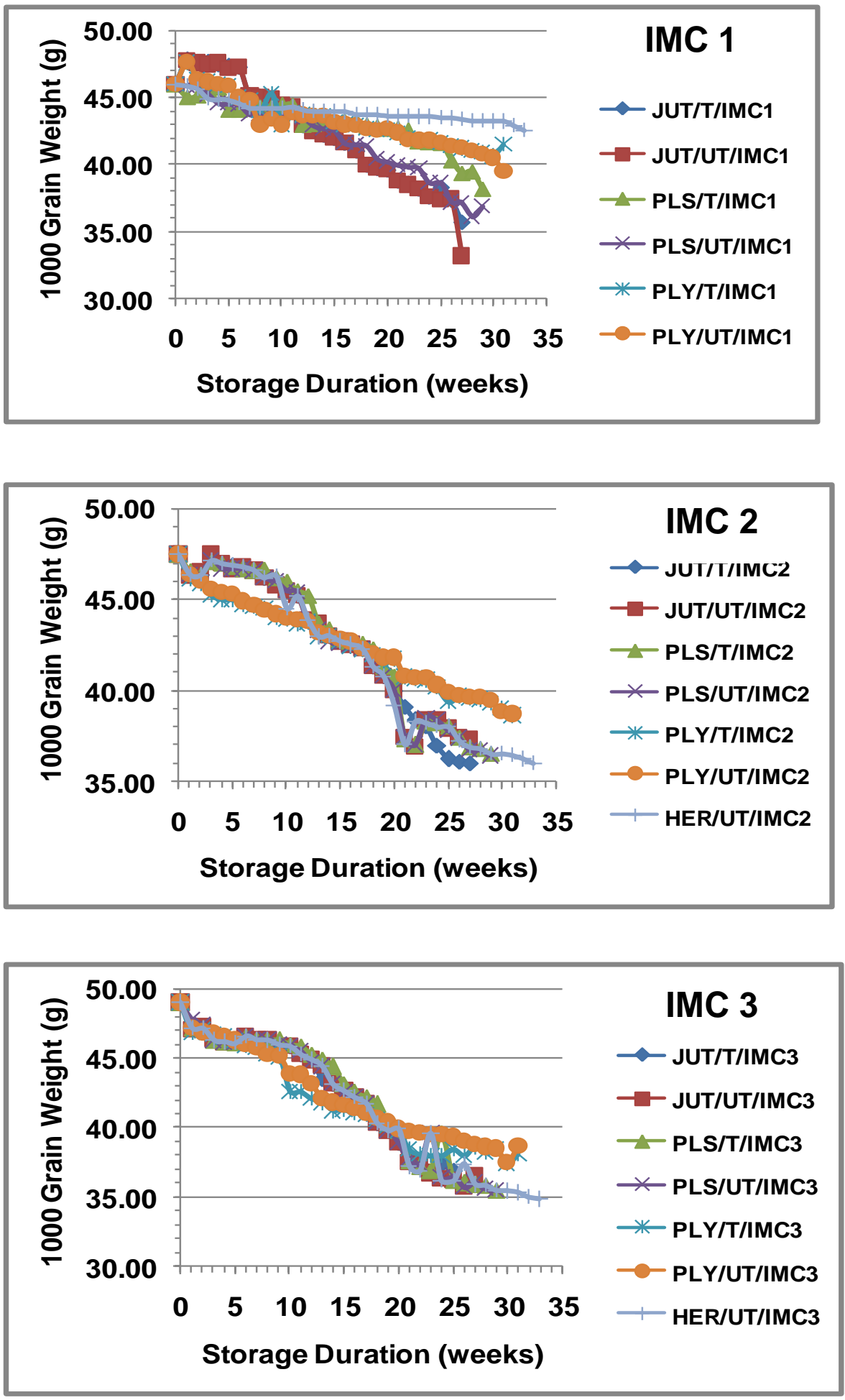

Fig 1 Variation in thousand grain weight with storage duration for differen bags and treatment at three different initial moisture contents 
Table.1 Summarized overall variation in thousand grain weight for all experimental combinations

\begin{tabular}{|c|c|c|}
\hline Treatment Combination & Max.Value (week no) & Min.Value (week no) \\
\hline JUT/T/IMC1 & $46.03(0)$ & $35.74(27)$ \\
\hline JUT/UT/IMC1 & $46.03(0)$ & $33.20(27)$ \\
\hline PLS/T/IMC1 & $46.03(0)$ & $38.19(29)$ \\
\hline PLS/UT/IMC1 & $46.03(0)$ & $36.90(29)$ \\
\hline PLY/T/IMC1 & $46.03(0)$ & $40.63(31)$ \\
\hline PLY/UT/IMC1 & $46.03(0)$ & $39.56(30)$ \\
\hline HER/UT/IMC1 & $46.03(0)$ & $42.58(33)$ \\
\hline JUT/T/IMC2 & $47.52(0)$ & $36.03(27)$ \\
\hline JUT/UT/IMC2 & $47.52(0)$ & $37.33(27)$ \\
\hline PLS/T/IMC2 & $47.52(0)$ & $36.53(29)$ \\
\hline PLS/UT/IMC2 & $47.52(0)$ & $36.41(29)$ \\
\hline PLY/T/IMC2 & $47.52(0)$ & $38.63(31)$ \\
\hline PLY/UT/IMC2 & $47.52(0)$ & $38.73(31)$ \\
\hline HER/UT/IMC2 & $47.52(0)$ & $36.03(33)$ \\
\hline JUT/T/IMC3 & $49.04(0)$ & $36.03(27)$ \\
\hline JUT/UT/IMC3 & $49.04(0)$ & $35.73(26)$ \\
\hline PLS/T/IMC3 & $49.04(0)$ & $35.51(29)$ \\
\hline PLS/UT/IMC3 & $49.04(0)$ & $35.51(29)$ \\
\hline PLY/T/IMC3 & $49.04(0)$ & $37.45(30)$ \\
\hline PLY/UT/IMC3 & $49.04(0)$ & $37.53(30)$ \\
\hline HER/UT/IMC3 & $49.04(0)$ & $34.83(33)$ \\
\hline
\end{tabular}


Table.2 UNIANOVA for effect of independent variables on thousand grain weight

\begin{tabular}{|c|c|c|c|c|c|}
\hline Source & $\begin{array}{l}\text { Type III } \\
\text { Sum of } \\
\text { Squares }\end{array}$ & df & $\begin{array}{l}\text { Mean } \\
\text { Square }\end{array}$ & $\mathbf{F}$ & $\begin{array}{l}\text { Sig. } \\
<0.05 \%\end{array}$ \\
\hline Corrected Model & $5.388 \mathrm{E} 8^{\mathrm{a}}$ & 641 & 840612.307 & .994 & $.530^{\mathrm{ns}}$ \\
\hline Intercept & $1.947 \mathrm{E} 7$ & 1 & $1.947 \mathrm{E} 7$ & 23.032 & .000 \\
\hline Bags & 217417.621 & 3 & 72472.540 & .086 & $.968^{\mathrm{ns}}$ \\
\hline Trt & 2745442.279 & 1 & 2745442.279 & 3.247 & $.072^{\mathrm{ns}}$ \\
\hline Imc & 5758012.141 & 2 & 2879006.071 & 3.405 & .033 \\
\hline Week & $7.369 \mathrm{E} 7$ & 33 & 2233096.910 & 2.641 & .000 \\
\hline bags $* \operatorname{trt}$ & 16355.524 & 2 & 8177.762 & .010 & $.990^{\mathrm{ns}}$ \\
\hline bags * imc & 592313.612 & 6 & 98718.935 & .117 & $.994^{\mathrm{ns}}$ \\
\hline bags * week & $1.178 \mathrm{E} 7$ & 87 & 135458.222 & .160 & $1.000^{\mathrm{ns}}$ \\
\hline trt $*$ imc & 6442716.055 & 2 & 3221358.027 & 3.810 & .022 \\
\hline trt $*$ week & 7.792E7 & 31 & 2513703.220 & 2.973 & .000 \\
\hline imc $*$ week & $1.446 \mathrm{E} 8$ & 66 & 2191632.810 & 2.592 & .000 \\
\hline bags $*$ trt $*$ imc & 31945.415 & 4 & 7986.354 & .009 & $1.000^{\mathrm{ns}}$ \\
\hline bags $* \operatorname{trt} *$ week & 434953.654 & 56 & 7767.030 & .009 & $1.000^{\mathrm{ns}}$ \\
\hline bags $*$ imc $*$ week & 3.002E7 & 174 & 172517.257 & .204 & $1.000^{\mathrm{ns}}$ \\
\hline trt $*$ imc $*$ week & $1.558 \mathrm{E} 8$ & 62 & 2513581.814 & 2.973 & .000 \\
\hline $\begin{array}{l}\text { bags } * \text { trt } * \text { imc * } \\
\text { week }\end{array}$ & 869510.022 & 112 & 7763.482 & .009 & $1.000^{\mathrm{ns}}$ \\
\hline Error & $1.086 \mathrm{E} 9$ & 1284 & 845422.362 & & \\
\hline Total & $1.638 \mathrm{E} 9$ & 1926 & & & \\
\hline Corrected Total & $1.624 \mathrm{E} 9$ & 1925 & & & \\
\hline
\end{tabular}

Observations were taken on daily basis during entire period of experimental storage in near vicinity of storage bags.

\section{Results and Discussion}

The summarized overall variation in thousand grain weight with minimum and maximum values under each experimental combination have been presented in Table 1 . It reveals that the TGW of the grain was initially in the range of 46.03 to $49.04 \mathrm{~g}$ for three initial moisture contents (IMC) which went down in the range of 33.20 to $42.58 \mathrm{~g}$ after 33 weeks of storage. The lowest TGW value was observed as $33.20 \mathrm{~g}$ for the experimental combination of JUT/UT/IMC1. The TGW of untreated Green gram grains in the jute bag was decreased from 49.04 to $33.20 \mathrm{~g}$ across all IMCs after 27 weeks of storage. Similarly TGW of treated Green gram grain in the jute bag was decreased from 49.04 to $35.74 \mathrm{~g}$ across all IMCs after 27 weeks of storage. The TGW of untreated Green gram grains in hermetic (HER) bags was decreased from 49.04 to $34.83 \mathrm{~g}$ across all IMCs after 33 weeks of storage. Decrease in TGW was due to loss of moisture from the grains and also insect infestation. 
Figure 1 is showing the variation in TGW with storage duration for different bags and treatment at three different IMCs. The TGW had a general decreasing trend across all experimental combinations with advancement of storage duration. Untreated Green gram grains stored in PLY bags had higher TGWs at IMC2 \& IMC3 as compared to JUT bags, PLS bags and HER bags in that order. Similarly treated grains behaved in the same manner across all combinations. The TGWs were lower at IMC3 as compared to IMC1 at all experimental combinations

Table 2 reveals that imc, weeks, imc*weeks, trt*weeks, and trt*imc*weeks had a significant effect on TGW. The imc having highest F-value affected TGW the most followed by trt, weeks and bags. The interaction of trt*imc was the most important interaction which affected TGW the most.

In conclusion, the thousand grain weight had a general decreasing trend across all experimental combinations with advancement of storage duration. Untreated Green gram grains stored in HER bags had lowest decrease in TGW at all IMCs compared to PLY bags, PLS bags and JUT bags in that order. Similarly treated grains behaved in the same manner across all combinations. The hermetic bags performed better allowing minimum reduction in thousand grain weights as compared to other types of bags. Hence the hermetic bags could be recommended for storing green gram safely for longer duration without affecting its quality.

\section{References}

Girish, O. K.; Tripathi, B. P.; Tomar, R. P. S. and Krishnamurthy. K. (1974). Studies on assessment of losses. Bulletin of Grain Technology, 12(3): 199-210.

Mutungi C.M. (2014). Storage of mung bean and pigeon pea grains in hermetic triplelayer bags stop losses caused by callosobruchusmaculatus. Journal of Stored Products Research. 58:39-47.

Kumari, A., Rajak, D., and Kumar, V. (2015). Comparative Study on Storage Behavior of Food Grain in Different Storage Bags. B. Tech. project report submitted to College of Agricultural Engineering, RAU, Pusa, Bihar.

Freitas, R. S. (2016). Hermetic storage for control of common bean weevil, Acanthoscelidesobtectus. Journal of Stored Products Research. 66:1-5.

Kumar, N., Kumar, S., Kumar, V. and Rajak D. (2016). Comparative Study on Storage Behavior of Wheat in Different Storage Bags. B. Tech. project report submitted to College of Agricultural Engineering, RAU, Pusa, Bihar.

Kumari, A. and Shrivastava, M. (2017). Storage behavior of green gram (Vigna radiate $L$.) in hermetic and other types of storage bags. Unpublished M. Tech. thesis submitted to Department of Processing \& Food Engineering, College of Agricultural Engineering, DrRPCAU, Pusa, Bihar.

\section{How to cite this article:}

Asha Kumari and Mukesh Shrivastava. 2019. Variation in Thousand Grain Weight of Green Gram Stored in Hermetic and Other Bags. Int.J.Curr.Microbiol.App.Sci. 8(06): 2174-2180. doi: https://doi.org/10.20546/ijcmas.2019.806.258 